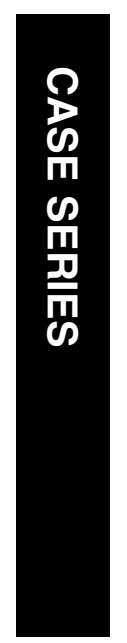

${ }^{1}$ Het Oogziekenhuis Rotterdam, Rotterdam Eye Hospital, Schiedamse Vest 180, Rotterdam, The Netherlands

${ }^{2}$ Department of Ophthalmology, University Hospital Brussels, Brussel, Belgium

${ }^{3}$ Department of Ophthalmology, Service of Medical Retina and Vitreoretinal Surgery, University Hospital of Ghent, Ghent, Belgium

Correspondence:

$M$ Wefers Bettink-Remeijer, Department of Ophthalmology, Het Oogziekenhuis Rotterdam, Schiedamse Vest 180, Postbus 70030, Rotterdam 3011 BH, The Netherlands Tel: + 3110 4017777;

E-mail:m.wefers@ oogziekenhuis.nl

${ }^{4}$ These authors contributed equally to this work

Received: 20 April 2009 Accepted in revised form: 25 August 2009

Published online:

23 October 2009

The first patient is shown as a case report poster at the Conference of the Dutch Ophthalmological Society in 2004

\section{Uveitis-like syndrome and iris transillumination after the use of oral moxifloxacin}

\begin{abstract}
Objective To report a newly recognized adverse effect of oral moxifloxacin. Design Observational case reports. Participants Five patients who used oral moxifloxacin therapy.

Main outcome measures In five patients, a uveitis-like episode followed oral moxifloxacin therapy, afterwards they experienced photophobia. At slitlamp investigation, the patients showed almost complete iris transillumination, not restricted to one sector, and persistent mydriasis of the pupil, with no reaction to light and no near reflex. Follow-up of 3 years in one of the patients showed no change of symptoms. Only in one patient, with a history of anterior uveitis, an anterior chamber tap was positive for herpes simplex genome. Only after the use of moxifloxacin did she experience continuous photophobia. Conclusions Iris transillumination and sphincter paralysis is a newly recognized adverse effect of oral moxifloxacin therapy. Eye (2009) 23, 2260-2262; doi:10.1038/eye.2009.234; published online 23 October 2009
\end{abstract}

Keywords: moxifloxacin; uveitis; iris transillumination; sphincter paralysis; adverse effect

\section{Introduction}

Moxifloxacin, 8-methoxyquinolone, is a synthetic broad-spectrum antibacterial agent. Pharmacokinetic studies have shown high tissue affinity. Whole-body scinti-radiography in rats after administration of radioactivelabeled moxifloxacin showed high concentrations in most organs, tissues, and melanin-containing structures in the
M Wefers Bettink-Remeijer ${ }^{1,4}$, K Brouwers $^{2,4}$, L van Langenhove ${ }^{2}$, PWT De Waard', TO Missotten ${ }^{1}$, JP Martinez Ciriano ${ }^{1}$ and E Van Aken ${ }^{3}$ eye, meninges, and hair follicles of the pigmented skin. ${ }^{1}$

Moxifloxacin is indicated for the treatment of acute exacerbations of chronic bronchitis, community-acquired pneumonia, and acute bacterial sinusitis. Recent studies have investigated intra-ocular concentrations of topically administered moxifloxacin ophthalmic solutions for prophylaxis against and treatment of intra-ocular infections. ${ }^{2}$

Numbers of prescriptions are rapidly rising in the Netherlands and in Belgium. We report five patients, who showed Iris transillumination and persistent mydriasis 3-4 weeks after oral moxifloxacin therapy.

To our knowledge, the extensive iris transillumination (with variable sphincter paralysis) as an adverse effect of oral use of moxifloxacin has not yet been previously reported.

\section{Case reports}

Five patients experienced a uveitis-like episode after the use of oral moxifloxacin with painful eyes; in the two patients seen in the acute stage, there was no severe anterior chamber reaction, only a few pigmented cells were observed. After 10-14 days, they developed a severe persistent photophobia, which interfered with their normal outdoor activities.

The first three patients were all referred to The Rotterdam Eye Hospital after the acute stage for evaluation of their uveitis and severe photophobia.

History revealed a uveitis-like episode 10-14 days after the use of oral moxifloxacin. Only the second patient (32-year-old female) had two earlier episodes of anterior uveitis in each eye in 2004. Examination of the iris in 2004 did not reveal any iris transillumination. In all three patients, a severe iris transillumination was visible (Figure 1). 


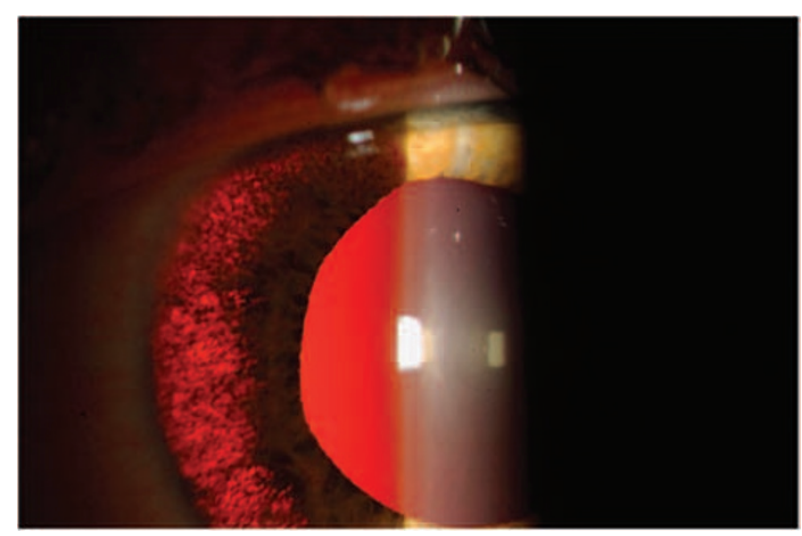

Figure 1 Patient 1.

Gonioscopy showed normal findings with mild pigmentation of the trabecular meshwork. Aqueous taps were performed, and were positive for herpes simplex genome only in the patient who had a former history of uveitis.

The fourth patient was referred to the university hospital of Gent, for evaluation of her photophobia and painful eyes. History revealed oral use of moxifloxacin, and aqueous tap showed no herpes simplex genome or serological evidence of herpes infection.

The fifth patient (74-year-old male) was referred to the university Hospital of Brussels for evaluation of a first episode of bilateral acute anterior uveitis. He presented with hyperaemic, painful eyes. Symptoms occurred 12 days after intake of oral moxifloxacin.

All patients used recommended doses (5-10 days 1 tablet).

Initial slitlamp examination showed bilateral aqueous cells, endothelial dusting, posterior synechia, segmental transillumination, and miotic, light-responsive pupils. Gonioscopy showed normal pigmentation of the trabecular meshwork. After treatment with topical prednisone, uveitis signs resolved and evolved into permanent diffuse iris transillumination and mydriasis (Figure 2).

In all patients, visual acuity remained unaltered. Elaborate work-up revealed no other cause of uveitis (see Table 1 for details of all patients). There were no signs of pseudoexfoliation syndrome. The iris transillumination and mydriasis showed the same pattern, without pigment dispersion on the surface of the iris or pigment accumulation in the chamber angle.

\section{Discussion}

We report five patients who showed severe photophobia due to almost complete iris transillumination and persisting mydriasis after a uveitis-like period after the use of moxifloxacin in otherwise healthy patients.

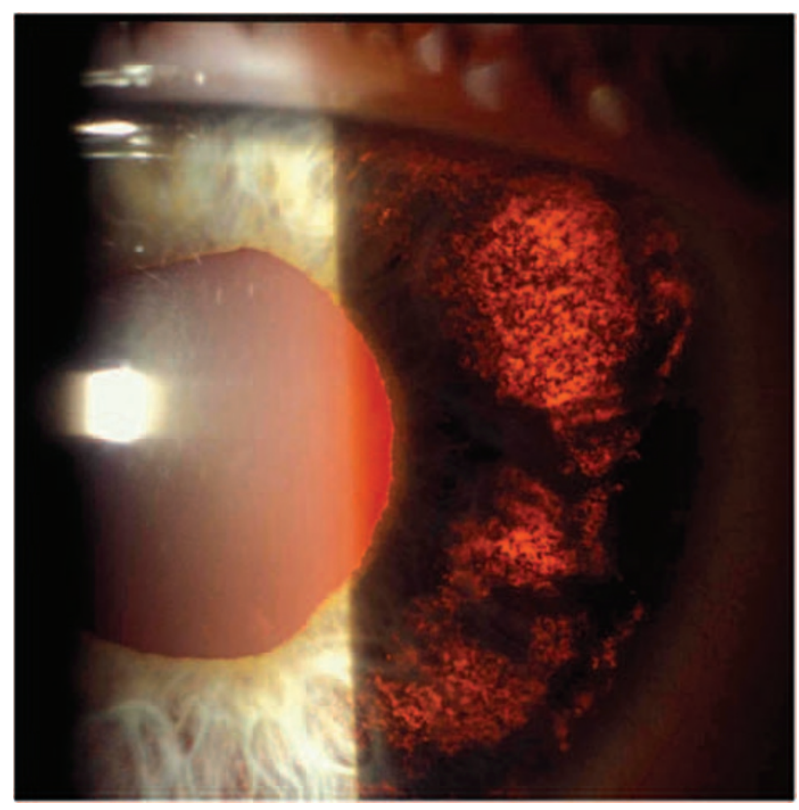

Figure 2 Patient 4.

One case of bilateral uveitis and pigment dispersion after the use of moxifloxacin has been reported in literature. ${ }^{3}$ In this case, pigment was dispersed over all the structures in the anterior chamber. In our patients, the pigment could no longer be detected.

Although herpetic infection is not completely ruled out by the negative aqueous taps by PCR $(66 \%$ sensitivity), ${ }^{4}$ the clinical pattern differs with herpetic uveitis, which generally shows a sectorial pattern of iris transillumination and unilaterality.

Herpetic genome was positive in the aqueous tap only in the patient with a previous history of anterior uveitis, but she only developed photophobia 3 weeks after the use of oral moxifloxacin.

In all patients, all other causes of uveitis were excluded.

The high tissue affinity of moxifloxacin, especially in melanin-containing structures of the eye, ${ }^{1}$ might induce phototoxicity in the iris pigment in susceptible patients when compared with photosensitive dermatitis caused by quinolones. ${ }^{5}$

Two of our patients used moxifloxacin during holidays abroad, where more light exposure is expected than in their home country. The other three had no extra light exposure.

We cannot exclude phototoxicity, but it is not likely the only cause. Extended use of sunglasses is, therefore, not yet recommended by us during and after the use of oral moxifloxacin.

Retinal pigment epithelium could be affected, ${ }^{6}$ but none of our patients showed any visible changes in the retinal pigment epithelium. 
Table 1 Signs and symptoms

\begin{tabular}{|c|c|c|c|c|c|}
\hline Patient & 1 & 2 & 3 & 4 & 5 \\
\hline Age and gender & 56-year-old male & 32-year-old female & 59-year-old female & 42-year-old female & 74-year-old male \\
\hline $\begin{array}{l}\text { Start of symptoms } \\
\text { after use oral } \\
\text { moxifloxacin (days) }\end{array}$ & $8-11$ & 10 & 14 & 10 & 12 \\
\hline Presenting symptoms & $\begin{array}{l}\text { Accommodation } \\
\text { problems, } \\
\text { photophobia, pain }\end{array}$ & Photophobia, pain & Photophobia, pain & Photophobia, pain & $\begin{array}{l}\text { Hyperemia eyes, } \\
\text { pain }\end{array}$ \\
\hline $\begin{array}{l}\text { Pupil slitlamp } \\
\text { examination }\end{array}$ & Mydriasis & Mydriasis & Mydriasis & Mydriasis & Miosis $\rightarrow$ mydriasis \\
\hline Inflammatory signs & None $^{\mathrm{a}}$ & None $^{a}$ & None $^{\mathrm{a}}$ & $\begin{array}{l}\text { Bilateral tyndall }+ \text {, } \\
\text { pigmentary cells, } \\
\text { endothelial dusting }\end{array}$ & $\begin{array}{l}\text { Bilateral tyndall }+ \text {, } \\
\text { posterior synechia, } \\
\text { endothelial dusting }\end{array}$ \\
\hline Iris transillumination & Severe & Severe & Severe & Severe & Moderate \\
\hline $\begin{array}{l}\text { Pigmentation } \\
\text { at gonioscopy }\end{array}$ & Normal & Normal & Normal & Normal & Normal \\
\hline Fundoscopy & Normal & Normal & Normal & Normal & Normal \\
\hline $\begin{array}{l}\text { Previous episode } \\
\text { of uveitis }\end{array}$ & No & Yes & No & No & No \\
\hline HSV aqueous humour & - & + & - & - & Not performed \\
\hline
\end{tabular}

an patients $1-3$, interval between the start of symptoms and examination in our clinic was $>4$ weeks.

We are aware of the fact that there may be a multifactorial aetiology of this adverse effect, but we are convinced that the use of oral moxifloxacin is one of these factors.

We expect a rise in the number of reports of this particular adverse effect after recognition of this condition.

\section{Summary}

What was known before

- One earlier report of uveitis-like syndrome.

What this study adds

- Severe iris transillumination; small series of patients; probably more will be reported.

\section{Conflict of interest}

The authors declare no conflict of interest.

\section{References}

1 Siefert HM, Kohlsdorfer C, Steinke W, Witt A. Pharmacokinetics of the 8-methoxyquinolone, moxifloxacin: tissue distribution in male rats. J Antimicrob Chemother 1999; 43(suppl B): 61-67.

2 Hariprasad SM, Blinder KJ, Shah GK, Apte RS, Rosenblatt B, Holekamp NM et al. Penetration pharmacokinetics of topically administered $0.5 \%$ moxifloxacin ophthalmic solution in human aqueous and vitreous. Arch Ophthalmol 2005; 123: 39-44.

3 Bringas Calvo R, Iglesias Cortinas D. Acute and bilateral uveitis secondary to moxifloxacin. Arch Soc Esp Oftalmol 2004; 79: 357-359.

4 de Groot-Mijnes JD, Rothova A, van Loon AM, Schuller M, Ten Dam-Van Loon NH, De Boer JH et al. Polymerase chain reaction and Goldmann-Witmer coefficient analysis are complimentary for the diagnosis of infectious uveitis. Am J Ophthalmol 2006; 141: 313-318.

5 Hamanaka H, Mizutani H, Asahig K, Shimizu M. Melanocyte melanin augments sparfloxacin-induced phototoxicity. J Dermatol Sci 1999; 21: 27-33.

6 Dayhaw-Barker P. Retinal pigment epithelium melanin and ocular toxicity. Int J Tox 2002; 21(6): 451-454. 